\title{
The Policy for Maintenance of National and Rural Roads Network in Albania
}

\author{
Dr. Alma Golgota \\ Aleksander Moisiu" Durres University \\ MSc. Diana Bardhi \\ Metropolitan University of Tirana
}

\begin{abstract}
This paper examines the effects of Territorial Reform on the maintenance of national and rural roads and makes recommendations regarding the implementation of maintenance under the new organisational structure. The background and logic behind those recommendations is elaborated in the body of the paper through summarising the principal actions and policies required to be adopted in order to achieve a proper standards of road maintenance under the new territorial strategy system of local government. It is important to recognise that the roads which will fall under the responsibility of the new bodies are just a part of the overall road system. They should not be considered in isolation and in some respects it is desirable that national policies and standards be adopted which will cover the whole of the road system. In these areas it is important that policy development take place in the context of cooperation between the various responsible institutions, primarily Ministry of Transport, Ministry of Local Issues, Albanian Roads Authority( ARA), Albanian Development Fund (ADF) and the new local government authorities, the LGA1s.
\end{abstract}

Keywords. national and rural, maintenance, inventarization, territorial

\section{Introduction}

There has been a steady process of decentralisation with the local government bodies carrying responsibility for a wide range of services and utilities including the local roads system. LGU finance comes from a mix of local funding in the form of taxes and fees and from unconditional grants from the centre. Overall this funding is roughly $50 \%$ local and $50 \%$ central.

This model of local government and decentralisation has suffered from serious challenges. These consisted of lack of a national policy development framework, lack of clear legal and regulatory framework, and extreme fragmentation of local authorities causing weak capacities of the local government. Lack of consensus and partisan behaviour among local elected officials, and lack of consensus inside local government associations have weakened local governance vis-à-vis the centre and caused delays in several important reforms. Additionally, the process of consultation between local government associations and the centre has been unsystematic and ad-hoc. Shared functions and competencies are vague, mainly as a result of a deficient and unclear legal framework regulating the structure, roles and competences of the central and local authorities at regional and local level.

Critically, fiscal autonomy of local government is also a challenge. Local authorities do not have appropriate financial resources or local revenues commensurate with their own and shared competences. LGUs are heavily dependent on financial assistance from the State

\footnotetext{
1 In order to avoid any confusion between the present organization of local government units and the proposed future organization, the proposed 61 new units have been referred to throughout this paper as Local Government Authorities (LGAs) rather than as Municipalities. 
The Government was well placed to support wide capital investments in rural and national road infrastructure network and in view of this program was a necessity to have a cataloguing of this type of road. base on their geometry, ownership, date of last investment. This catalogue can be used to establish a comprehensive national roads database as well as serving the LGAs individually. Initial field cataloguing need only comprise complete GPS data for road alignment. However, with suitable equipment, this exercise can also provide photographic records along all roads without significant additional effort.

Cataloguing should include National as well as LGU roads since the National network is not clearly defined and is likely to be handed over in part to the LGAs. Cataloguing should be carried out through ADF teams working with local staff. Cataloguing of the more remote commune roads is particularly urgent since inputs from existing commune staff may be essential to identifying these roads. It is desirable that LGA staff should have some ownership of the project through participation in the cataloguing process. It is acknowledged that there is a conflict between this requirement and the need to involve commune staff. Suggestions are made for resolution of this conflict through the use of a 2 stage cataloguing exercise. The cataloguing exercise may be extended to include ARA roads should ARA consider this necessary to gather additional data. The final roads catalogue should include, or be expandable to include, the complete road system of Albania. Cataloguing should be carried out through ADF and LGA staff teams working together. LGA staff must feel that they have ownership of the project and commune staff are likely essential to full identification of remote roads. All roads to be driven for their full length to record complete GPS location data. In the case of larger municipalities only, existing mapping may be used rather than drive over location.

\section{A Roads Database}

A basic computerised GIS database of roads can form the basis for comprehensive estimates of maintenance requirements. The basic database will comprise all data collected during the Cataloguing exercise defined above. The database will provide a complete GIS compatible mapping of the catalogued road system. Once established the database can be expanded to include any and all additional details of the road system through entry of additional data on an ad hoc basis. Database will differentiate between Fixed data (eg. road sections location and length, width, structure locations)Variable data (eg road roughness, structure condition, general condition data). The database should be established on a central computer and be accessible to all LGAs for information entry and retrieval. Access via internet connection and via 3/4 G phone system. Set up computer database/GIS programme. Input data from cataloguing to computer. Establish database system using outside consultants as required. GIS or Engineer expert receives data from field teams and enters into Database software. Ensures that all field data is database compatible and error free. Computer system including backup system. Software. Initially as for Cataloguing but with a continuing maintain and update operation.

\section{Reallocation of National Roads}

Current records of the National road system are inconsistent. The Cataloguing exercise should include the present National roads to define them and to locate them in a system consistent with the local roads catalogue. The National Roads should be reallocated between ARA and LGAs Approximately half the existing National road system provides links between new LGA centres and existing Commune centres (and, in a few cases, between remote communes and nearest National Road lying outside the LGA)- these are called the main Roads many of these main roads have been improved under SLRP1; there is a commitment to lenders to transfer improved National roads to ARA. It is proposed that Main roads should be transferred to ARA and the balance of National Roads transferred to LGAs. This should satisfy most of the Lender commitments. Transfer of Main roads to ARA should be the basic principal behind reallocation of National Roads but can be reviewed with ARA and LGAs on a case by case basis. Non Main roads will not be transferred to ARA. Some Main roads may be retained by LGAs if it is decided that this is expedient. Review National roads for transfer to LGAs and to ARA on case by case basis using the Main roads principle. Make any necessary orders or pass legislation to effect the agreed transfers. The initial central review to be carried out by ADF in conjunction with ARA and MoT. Local reviews to follow with LGAs. Finalise transfer proposals with any legislative action required. ADF to negotiate with donors to resolve any conflicts with existing loan commitments. Basic proposals for transfer of National roads to be fixed within the time of

\footnotetext{
1 SLRP: Secondary and Local Roads Project; improving 1500 kilometres of Regional and LGU roads 
whole urban planning process is over, almost the end of June 2016. Subsequently finalised with LGAs when these are established and when cataloguing is complete.

\section{Classification of Roads}

Review the existing classification criteria and expand/modify to suit new situation. Avoid unnecessary changes Road classification to be reviewed mainly to reflect redistribution of Regional Roads, Align road classification with Maintenance Responsibilities Correct any anomalies identified during cataloguing/review Review LGA roads to identify Urban and Primary and Secondary Rural roads as defined in the text of this paper. Central review and definition of criteria by MoT, ARA and ADF. ARA and LGA level reviews to establish classification within the national and each local road system. Working group from ADF, ARA and MoT to review classification system and guidelines. ADF to define preliminary classifications for all LGA roads and then to finalise with LGA representatives. Initial review phase prior to establishment of LGAs. Finalise road classifications within LGAs as soon as possible after these are established and staffed.

Levels of Service and Maintenance Standards

A national system of Levels of Service and corresponding Maintenance Standards should be established. Levels of Service are the qualitative standards which users can reasonably expect from different classes of road. Maintenance Standards are numerically defined physical parameters which must be achieved to provide the various Levels of Service.

As a minimum, setting up a system of standards will require participation of ARA, MoT, ADF; at some point representation for LGAs would also be desirable. The object should be establish appropriate standards for each class of road and traffic level.

This is not a trivial exercise. Standards need to be set according to economic criteria considering maintenance costs, road conditions, vehicle operating costs, values of time and other factors. Establishment of National Standards to be done within 12 months. Establish appropriate Levels of Service for the roads within each LGA in accordance with these standards and compare with actual levels at present.

\section{Common Contracts}

A common family of standardised maintence contract forms should be established for use on most road maintenance works in Albania. Three common contracts would cover at least,

\section{Performance Based Maintenance Contracts}

\section{Admeasurement Contracts}

Simplified Performance Based Maintenance of low volume gravel roads.

Contract forms to be established jointly with ARA and used by ARA and all LGAs. Use of standard contracts makes tendering much simpler for contractors and makes evaluation much simpler for the Employer(s)Standard contracts can be expected to keep costs down over the long term. Prepare standard contract forms to cover $95 \%$ of maintenance requirements for national use. Joint ADF/ARA working group to agree scopes and prepare draft contracts. To be reviewed/commented/approved by MoT and appropriate legal authorities. Possibly make use of Consultants presently employed with ARA and ADF.

\section{Road Roughness and Traffic Volumes}

Road Roughness is a key indicator of paved road condition and maintenance requirements. Historical roughness data is a key indicator of the rate at which any specific pavement section is deteriorating. There are presently no comprehensive roughness surveys being carried out. Traffic volumes are a second key indicator of a roads importance and of the economic justification for additional maintenance. There are presently no comprehensive traffic surveys being carried out. Roughness of paved roads and traffic volumes on all roads should be measured regularly: 
Roughness at annual intervals

Traffic at annual intervals with additional counts to establish and then control seasonal variations.

Decide how to set up a unit or units able to carry out these activities. Roughness should utilise a national unit. Traffic counting could be done at the LGA level with a national unit carrying out verification checks. Set up and operate the units possibly with outside funding assistance to set up. Liaise with ARA to mesh with their activities in this area.

\section{Funding and Costs of Maintenance}

LGUs do not spend enough on maintenance. Money spent of maintenance now saves much more money being spent on rehabilitation later LGUs use "investment" projects to make good some of their maintenance failings. This results in complete blurring of the real total of expenditures on maintenance. Further, LGU accounting formats do not allow for the clear identification of all direct maintenance costs/expenditures. It is estimated that total LGU expenditure (Municipalities and Communes) on maintenance and on "Investment" in lieu of maintenance is around ALL 1. 95 billion and that this should rise to ALL 3.5 billion if a reasonable standard of road maintenance is to be achieved. These figures do not include the present Regional Roads invested from ARA. These figures assume only the most basic standards of maintenance (effectively, just maintain access) for the bulk of the Rural gravel roads

These figures do allow for an element of "improvement through maintenance" on the poorer surfaced roads. Provide LGAs with the requisite funds to meet their responsibilities. Implement controls to ensure that LGAs spend appropriately on road maintenance. This may involve specifying percentages of funds for certain activities or the provision of separate funds for maintenance; alternatively LGAs could submit draft budgets for approval; they would then be tied to the approved budget. Review the system of accounting proformas/subheads and revise to ensure that all types of expenditures are clearly identifiable in the permanent records. Review and revise the overall systems for allocating funds to ensure they provide incentives to maintenance rather than "investments" to make up for lack of it. In the longer term, use a maintenance management system to estimate the required total annual spend on maintenance and the optimum distribution of available funds.

\section{Decentralisation and Local Government Reform}

The whole background to, and the proposals for, the reform of Local Government in Albania are available in the report on the National Crosscutting Strategy for Decentralization and Local Governance (NCSDLG) 2014-2020. It would be pointless to repeat the information provided in that report in detail here, however, a brief recapitulation of the salient points may be of help in understanding the background to the contents of this paper.

Government in Albania is currently effectively organised on three levels:

The Central Government,

Twelve Regions or Qarks

61 Municipalities

There are also 36 Districts, however, these play only a minor role and do not affect consideration of road maintenance issues.

This organisation model dates from the adoption of the Constitution (1998) and the National Decentralization Strategy, adopted in January 2000. The most important specific step was the approval and implementation of the Law No. 8652 of 31 July, 2000, "On the Organization and Functioning of Local Government", which sanctions the rights and authorities of the local governments units.. 
The situation and these criticisms from the Strategy Report are general and relate to the whole field of LGU operation. Since the maintenance of the local road systems is the province of the LGUs, the defects in LGU governance and funding are of critical importance in considering the ability and effectiveness of LGUs in the field of road maintenance.

The present proposals for Territorial Reform are a part of a broader strategy to improve the quality and standards of local government and to further the process of decentralisation.

It has become clear that a major factor in the poor and confused governance exercised by the present LGUs is their small size. This problem has actually grown worse over the years as a result of migration from the countryside to the cities and there are now considerable numbers of LGUs with populations of just a few thousand and some with populations less than one thousand. The proposed Territorial Reform is partly an effort to improve this situation by reducing the number of governing units to create a more limited number of reasonably sized entities which should be more suited to exercising the decentralised responsibilities which they have been given.

This Paper is concerned not with the general philosophy of decentralisation nor, directly, with the overall range of devolved responsibilities; its purpose is to examine the present state of local roads maintenance for national and rural ones, to assess how this will be affected by the proposed Territorial Reforms with the creation of the 61 new LGAs and to consider what measures might reasonably be implemented to assist the new LGAs in the improved maintenance of the road systems which they will inherit from the present LGUs and, probably, from the Qarks.

To supplement this brief appreciation of the situation regarding Decentralisation and Territorial Reform a short assessment of the legal background and possible future legal requirements is presented as below.

\section{ROADS MAINTENANCE CURRENT SITUATION}

The existing Albanian legal framework on road maintenance is a product of different and intersectorial rules, essentially based on the road transport rules, such as the Albanian Road Code1 and respective bylaws, and the law on local governmental units2. Several other legal provisions are correlated to this issue.

During recent years the Albanian government has been focused on improvement of the road infrastructure with the intent of helping the economic development of the country. The road structure was not satisfactory and internal financial resources have never been sufficient to permit the full development of the road system. In an effort to improve this situation Albania has, in recent years, received conspicuous donations and grants for road improvement from foreign entities, such as the World Bank, EIB, KFW, EBDR, etc.

Despite these investments, to date the whole situation of the road system remains problematic. These problems do not concern only the infrastructure and budgeting issues, but also require an improvement of the legislation in force and the implementation procedures. Furthermore, legal questions will now arise as a consequence of the new territorial reform of the local administrative units and any corresponding decentralization of competences. This specific topic is analysed in Section 2 below.

With regard to the development of a sustainable road maintenance system, the current legislation and the de facto situation demand improvements. Based on the Secondary and Local Roads Programme analysis, it seems that the existing legislation requires improvements focused on road maintenance issues. As detailed in the policy paper, there are different aspects that are not transparent and clear to date. A legal review of such aspects is detailed in this document and suggestions for improvement are provided.

\footnotetext{
1 Law 8378 dated 22.7.1998, "Road Code of the Republic of Albania", as amended

2 Law 8652 dated 31.7.2000, "On the organization and functioning of the local government", as amended
} 
Currently, the management of roads is handled either by the central government or by the local governmental units. National/State roads are administered by the central government through the Albanian Road Authority, an entity created specifically for this purpose by a special law1.

With regard to local government units; qarks, municipalities and communes, the administration and the maintenance of roads are competences, specifically granted by the legislation on local governmental to LGUs as a derivation of the decentralization principle and the autonomy of LGUs granted by the constitution2.

In addition to the above competences within their territorial jurisdiction LGUs have also other competences related to roads management, based on the Road Code provisions3, such as the classification of roads, the creation of the respective road maps, keeping the road cadastre.

\section{The Present Road System}

The present system of road classification in Albania is theoretically a functional system based on an appreciation of the functions of each road. Functions range from use by transnational traffic and communications between the major cities at one end of the scale to providing access to remote mountain villages at the other.

The functional classification is reflected in the de facto division of the road system into three main classes or groups, each with its own administration:

The National Network administered by the Albanian Roads Authority (ARA)

The Regional Network (Secondary roads) administered by the Qarks

The Urban and Local roads administered by the LGUs (Communes and Municipalities)

The basic system has, however, become corrupted to some extent over time with roads being effectively reclassified in order to reallocate them to a different maintenance organisation in the hope that they will receive improved maintenance and not because of any change in their function.

This degradation of the system was started through the perceived inability of some Qarks and LGUs to carry out their maintenance functions adequately. Roads were therefore transferred "up" the system to the higher organisation which was considered more able to handle the maintenance. The Secondary and Local Roads Project (SLRP) is further confusing this situation through lender's covenants requiring that rehabilitated secondary roads (or all Secondary roads) be allocated to ARA after completion without regard to their logical place in the system.

The national roads form the backbone of the countries road system and are managed and maintained by the Albanian Roads Authority (ARA, successor to the General Roads Directorate, GRD). The ARA was set up with the idea of removing roads administration from the general political arena, however, the original intended level of independence has not been achieved and the ARA remains very much a part of the political system. The national roads comprise the principal through routes of the country. They provide direct service for cities and larger towns and the main border crossing points, generating and attracting a large proportion of trips and forming the key integrated network providing access to the subsidiary routes and locations. The National network is well defined and comprises some 3285 kilometres of road which will increase to about 3975 kilometres when currently planned transfers of rehabilitated Secondary roads from Qarks to ARA are finalised. If all Secondary roads are transferred, the national network will increase to around 7000 kilometres.

The Regional, or Secondary, roads are the next lower tier of roads in function and importance; they link lesser cities and provide links for all the primary centres, communes and municipalities, both to each other and/or to the main national

\footnotetext{
1 Law 10164, dated 15.10.2009, "On the Albanian Road Authority"

${ }^{2}$ Article 13 of the Albanian Constitution: "Local Government in the Republic of Albania is based on the principle of decentralization of power and exercised according to the principle of local autonomy".

${ }^{3}$ Articles 13 and 14 of Albanian Road Code 
network; they provide the necessary additional linkages which are essential to facilitate communications at the regional level and to feed traffic into the national network. These regional roads are administered by the twelve regional authorities, the Qarks, and currently total about 3700 to 3900 kilometres before any transfers to ARA are taken into account. The exact length is uncertain because Qark responses to a variety of questionnaires have provided conflicting details of their road systems.

Local roads are the lowest tier in the system and provide communications within the local government units; they provide for internal communications within the LGU and feed traffic to the regional road network and to the national road network where direct connections exist. Local roads are in the ownership of the LGU (commune or municipality) within which they lie and the LGU is responsible for their maintenance. Local roads may conveniently be considered in two subclasses:

Urban or municipal roads

Local Rural Roads

The urban and municipal roads are a mix of paved and gravel roads whilst the local rural roads are mainly gravel surfaced although with some (usually short) lengths of asphalt paved road, generally in the more important commune and village centres.

The strict legal situation is somewhat more complex. Up to 1998 all the roads were under the jurisdiction of the GRD. Whilst the budgets for national roads were awarded separately and specifically for the national roads, the financing of the regional and communal roads was made available through the award of unconditional grants to the regional authorities. These grants also included provisions for the services and expenditures for other departments for which the regional authorities had responsibility. The decision for how much of the grant was to be expended on the regional and communal road networks was therefore the responsibility of the regional councils.

The Council of Minister's Decree no. 405 on the national and rural road network administration in the republic of Albania was issued on the 8th January 1996.

Based on the proposal of the respective Ministries of Construction and Ministry of Tourism the Council of Minister's Decree defined the roads to be under the administrations, respectively, of GRD, Qarks and LGUs (Communes and Municipalities). The decree also required the Ministries to issue guidelines, complete the road inventory and develop organisations to administer the road networks.

The Council of Ministers Decree no. 104, date 20. 2. 2003, included the division of rural roads into communal rural roads and regional rural roads and definitions of these roads as follows:

Communal rural roads are those connecting:

The commune centres with the villages and settlements or the roads connecting the villages with each other within the jurisdiction of a commune.

Regional rural roads are those connecting:

The commune centres with district centres or the national road network; road between two or more communes;

Roads that have a special importance, such as the roads connecting the commune centres or villages with museums, archeological centres or other tourist zones".

However, this decree is no longer in force following the issue of the Albanian Road Code which now has the legal authority to administrate and classify the road network and provides a more complex version of this classification system thus:

"According with their constructive technical and management characteristics roads shall be classified as following: 
Highway

Main interurban road

National interurban road

Main urban road

National urban road

Rural road"

Fortunately, it then goes on to provide a simpler regime, stating:

"According their use, function and needs to the administrative character these roads are divided into:

National roads, whose entity property is the state;

District road whose entity property is the district (Qark)

Communal (urban) roads whose entity property is the municipality

Interior roads whose entity property is also (depending on the circumstances) the municipality or commune. "

As will be seen, this second definition is substantially in accord with the simple descriptive classification set out at the start of this section and effectively reflects the actual situation at present. For practical purposes the general principle in defining the regional roads has been to maintain the provision of Decision 104 given above: Regional rural roads are those connecting the commune centres with district centres or the national road network, together with roads between two or more communes and roads that have a special importance, such as the roads connecting the commune centres or villages with museums, archeological centres or other tourist zones.

Network lengths

\section{1 The National Network}

The national network is under the sole administration of the ARA. The ARA is an organised institution with proper records of the roads under its control. The result is that the national network is properly defined and catalogued. At 2013 the network comprised a total of 3285 kilometres of road including motorway, dual carriageway and single carriageway road lengths. Whilst most of the national network is paved, either asphalt or cement concrete, there remain some sections which are still only gravel paved.

As a result of transfers of rehabilitated Secondary roads from Qarks to ARA commencing in 2014, the length of road administered by ARA is rising substantially. It is not clear if these transferred roads are now to be considered as a part of the National Network or if they are to be classified separately as Secondary or Regional roads maintained by ARA. The length involved is discussed in the following Section.

\section{2 The Regional Roads}

The regional roads are administered by the 12 Qarks. The length of the Regional road system is less clear than that of the national network.

Lengths of regional road for each Qark have been considered based on listings in a variety of places.

The central database 
Tables in the 2009 SLRP reports by Roughton

Returns by all 12 Qarks to Ministry of Transport query in 2014

Statements, by some Qarks only, in response to queries raised by this project in 2014. In a few cases these queries are answered twice - with different results.

Further responses by Qarks to additional requests made to try and clarify the situation October 2014

As can be seen from examination below of the lengths recorded in this table there are some very substantial discrepancies regarding the lengths of road under each Qark's responsibility. Some of these discrepancies might be due to confusion over the inclusion or omission of roads scheduled to be handed over to ARA but this cannot explain cases where the regional road length has apparently increased over the last 5 years nor can it account for cases where the length has apparently decreased by more than the amount scheduled for handover. In addition there seems no good explanation for the difference between the central database lengths and the SLRP report lengths from 2009 since we understand that these were both compiled on the basis of reports from the Qarks at that time. Additional work is needed to determine the precise lengths of the Regional Roads and to define any roads which are not strictly Regional Roads but are nevertheless under Qark control. However, for present purposes, it is probably sufficient to state that the Regional roads total about 3,800 kilometres, of which 690 kilometres have definitely been or are due to be handed over to ARA under the SLRP commitment that ARA will take over maintenance of rehabilitated Secondary Roads.

The further or alternative commitment, that all Secondary roads will be handed over to ARA for maintenance is discussed separately below.

The details of these various listings are given in the table below:

Tab.

1

\begin{tabular}{|c|c|c|c|c|c|c|c|}
\hline Qark & ADF Database & SLRP Report 2009 & $\begin{array}{l}\text { Qark Responses to } \\
\text { Questionnaire } 2014\end{array}$ & $\begin{array}{l}\text { Qark list of } \\
\text { Roads } 2014\end{array}$ & $\begin{array}{l}\text { Qark Responses to } \\
\text { MoT } 2014\end{array}$ & $\begin{array}{c}\text { Qark Response to ADF } \\
\text { Question Supplement } \\
2014\end{array}$ & $\begin{array}{l}\text { Total Length } \\
\text { Scheduled for ARA } \\
\text { Handover }\end{array}$ \\
\hline Berat & 199.1 & 199 & 88.6 & 88.6 & 80.6 & $112.6 *$ & 50.9 \\
\hline Diber & 403.2 & 403 & & & 347.2 & $403.2 * *$ & 52.9 \\
\hline Durres & 134.4 & 90 & 116 & & 115.5 & 115.5 & 32.5 \\
\hline Elbasan & 471.8 & 478 & & 528 & 562.1 & 562.1 & 73.9 \\
\hline Fier & 368.3 & 368 & $437.7 * * *$ & 454.5 & 417.2 & $410.3 * * *$ & 78 \\
\hline Gjirokaster & 225 & 199 & & & 220 & & 15.2 \\
\hline Korce & 541.6 & 591 & 584 & 578.7 & 624.3 & & 28.1 \\
\hline Kukes & 328.6 & 340 & 183.5 & 183.5 & 183.5 & & 76 \\
\hline Lezhe & 386.3 & 296 & & & 400 & & 45.8 \\
\hline Shkoder & 302 & 302 & & & 404 & & 140.5 \\
\hline Tirana & 276.69 & 277 & & & 97.7 & 278.29 & 71.16 \\
\hline Vlore & 147.6 & 249 & & & $140.7 * * * *$ & 271.7 & 24.8 \\
\hline Total & 3784.59 & 3792 & & & 3452.1 & & 689.76 \\
\hline
\end{tabular}

Notes

* includes Berat - Sinje (17.9 km) which has been handed over to ARA

** includes $55.5 \mathrm{~km}$ listed for handover to ARA

*** Fier supplied 2 lists of roads. 410.3 the most recent. 437.7 is dated 12/2012

**** This length quoted to MoT is Vlore District not Qark

\section{Urban and Communal Roads}

The total length of Urban and Communal roads is a far more obscure and contentious problem than that of the National and Regional elements of the system. 
The central records show that there are approximately 6,060 kilometres of communal roads. In the course of preparing this paper and in the initial phases of this project a total of some 53 communes and 11 municipalities have been interviewed. The total length of communal roads within the 53 communes, according to the details provided by the local administrations, is 2549 kilometres compared with a length of 805 kilometres from the central record. If this scale of under-recording is duplicated throughout the 308 communes then the overall length of communal road is likely to be around 19,000 kilometres. We believe that this is far higher than any previous estimate of LGU communal road length.

Although we have been unable to locate comparable central records of municipal road lengths, the figures which we have found in the field are much less daunting. Eleven municipalities have been examined (including the large municipalities of Durres and Fier) and the total length of municipal roads within this sample is just 407 kilometres split roughly 50/50 between Paved and Gravel roads. Disregarding Tirana itself, the implication here is that the total length of municipal roads may be of the order of 1300 kilometres of paved road and 1300 kilometres of gravel roads. However, this is a very rough extrapolation and it must be noted that we have serious doubts about the road lengths quoted in respect of Durres (too low) and Fier (too high).

In any case, in round figures, the Urban and Communal road system is expected to have a total length in excess of 20,000 kilometres.

The principal reasons for the very high value of the estimated length of communal roads are probably twofold:

Initial misreporting

Communes taking responsibility for routes not previously reported as roads.

It is our understanding that central records relating to commune road length were compiled on the basis of returns made by the Qarks in the period 2007-9. It is not clear that the Qark returns were based on details submitted by the communes. In some cases communes have noted that the central list of roads definitely omits significant commune roads linking major villages to the commune centre.

In discussion with various communes it seems that for many of the more obscure village roads they see their obligation as one to keep the road open rather than as a comprehensive maintenance obligation. It would appear that a large number of existing access roads may never have been formally recorded beyond the commune level as roads under maintenance.

Despite the expressed preference for carrying out their own maintenance, the Qarks interviewed generally had very little equipment to do so and their activities are largely limited to straightforward routine maintenance tasks executed by labour, as shown in table below:

\section{Tab 2: The quantity of carrying in different qarks}

\begin{tabular}{|l|c|c|c|c|}
\hline \multicolumn{1}{|c|}{ Qark } & Trucks & Exacavator & Roller & Tractor/Trailer \\
\hline Fier & 1 & 1 & 1 & \\
\hline Kukes & 1 & $2(1)$ & & \\
\hline Korce & 4 & 1 & & 3 \\
\hline Durres & 1 & 2 & 1 & \\
\hline Berat & 1 & & & \\
\hline
\end{tabular}

None of these Qarks has any obvious capability to deal with asphalt paving works. The general scale of equipment is too low to draw any worthwhile conclusions except to note that it confirms the acknowledged inability to deal with anything but routine maintenance. In the case of those Qarks with an excavator this appears to be used to deal with drainage problems (Durres and Fier) and with minor landslides (Korce and Kukes). 
The costs of maintaining their road networks vary considerably from Qark to Qark. The costs given in the table below are based on reported expenditures from Qarks for the year 2013.

\section{Tab 3: The costs of maintaining the road}

\begin{tabular}{|l|r|c|r|r|}
\hline \multicolumn{1}{|c|}{ Qark } & $\begin{array}{r}\text { Road } \\
\text { Length }\end{array}$ & $\begin{array}{c}\text { Percent } \\
\text { of Paved } \\
\text { Road }\end{array}$ & $\begin{array}{c}\text { Total Cost of } \\
\text { Maintenance } \\
\text { (ALL/year) }\end{array}$ & $\begin{array}{c}\text { Cost of } \\
\text { maintenance/ } \\
\text { Km/year (ALL) }\end{array}$ \\
\hline Elbasan & 528.0 & & & 140,000 \\
\hline Fier & 437.7 & $71 \%$ & $40,100,000$ & 91,615 \\
\hline Kukes & 183.5 & $26 \%$ & $25,030,000$ & 136,403 \\
\hline Korce & 578.0 & $21 \%$ & $60,470,000$ & 104,619 \\
\hline Durres & 116.0 & $64 \%$ & $31,984,000$ & 275,724 \\
\hline Berat & 88.6 & $32 \%$ & $20,695,000$ & 233,578 \\
\hline
\end{tabular}

Note: Elbasan figure based on estimated cost using contractors

It is noticeable that the Qarks with the least road (Berat and Durres) have the highest rates per kilometre for maintenance whilst those with the most road have the lowest rates. The overall average cost of maintenance across the 6 Qarks considered, works out to ALL 130,550 per kilometre per year.

\section{Territorial Reform and its Implications}

In order to understand the implications of reform it is necessary to have a picture of what the new LGAs might consist. To create such a picture we have examined five of the proposed new LGAs each of rather different character:

Kukes. Mountainous. Moderate Central Municipality. 928 Sq. km. Population 48,000.

Pogradec. Semi mountainous. Moderate Central Municipality. 610 Sq. km. Population 61,500.

Durres. Coastal. Dominated by a large municipality. 281Sq. km. Population 168,500.

Fier. Coastal, Large central municipality. 630 Sq. km. Population 120,500.

Polican. Central, mountainous. Only 3 constituent LGUs. 286 Sq. km. Population 11,000.

Each of the communes and municipalities (the LGUs) comprising the five selected proposed LGAs has been asked to complete a questionnaire to provide details of the LGU covering its roads and road maintenance capacity and its funding. Each of these LGUs has then been visited by a Consultant's team member to discuss the questionnaire response and to amplify data in respect of the roads within the LGU and the LGUs actual responsibilities and activities in respect of roads maintenance and improvement. By amalgamating these responses we have attempted to gain a picture of what the proposed LGAs obligations and possible funding will be in respect of road maintenance. This will give a picture of the situation with which the new LGA administration must deal.

In addition to visiting all the component LGUs we have also visited the relevant Qarks to review their present road maintenance capabilities and obligations. This may become an important issue if the Qarks cease to have responsibility for roads maintenance and their obligations are passed, in whole or in part, to the LGAs.

The proposed Kukes and Pogradec LGAs are the only ones of the five LGAs studied which conform exactly to the old District outline. Two others, Durres and Fier, are essentially old Districts shorn of some of their constituent communes whilst a fifth, Polican, is a new construct. 


\section{Definition of Road Catalogues}

The changes outlined above would not alter the principle of functional classification but would provide for the distribution of the Regional roads to ARA and to the LGAs. This process of distribution would automatically include a review the current Qark road catalogues eliminating the current anomalies of roads which have been wrongly defined as Regional. They will also provide an opportunity for the ARA to review its own road catalogue and provide a clear definition of a primary and secondary national network. It is highly desirable to rationalise both ARA and LGA catalogues to remove anomalies which have accrued over the years.

\section{1 The Costs of Road Maintenance}

Section Error! Reference source not found. examines expenditures on road maintenance within the Qarks, Municipalities and Communes and estimates current expenditures per kilometre at:

Qarks ALL 130,000 per km. per year

Municipalities ALL 340,000 per km. per year

Communes

$$
\text { ALL 40,000 per km. per year }
$$

These figures illustrate the estimated current maintenance rates based on ESTIMATED road lengths. It is also advisable to consider the absolute estimated expenditures:
6 Qarks:
ALL 178 million (12 Qarks
356 million)
11 Municipalities
ALL 133. 5 million (75 Municipalities
910 million)

53 Communes

ALL 96. 7 million (308 Communes

562 million)

These figures are very low. They effectively cover the costs of routine maintenance only, with no allowance for periodic maintenance or for improvements incurred as a result of inadequate maintenance.

These costs do not include substantial management costs, especially for the communes where there is really no element of management at all included within the costs. The commune accounting and record systems do not break out many of the costs associated with maintenance, in general they detail specifically only the costs of materials supply, casual labour and,sometimes, permanent labour. Voluntary labour is, of course, not costed, and the costs of permanent labour are not always clearly assignable.

Routine maintenance alone is not the major element in a fully costed, fully functional maintenance regime. Roads deteriorate and incur higher maintenance costs as time goes by until periodic maintenance is required. The full maintenance costs can only be estimated by considering the complete cycle of events over a prolonged period.

Routine and Periodic Maintenace costs per km. Annualised over 20 years (ALL)

\begin{tabular}{|l|c|c|r|r|r|}
\hline Growth Rate & $2.50 \%$ & Platform Width & 6.7 & 6.7 & 6.7 \\
\hline & Traffic AADT & 1000 & 500 & 2000 \\
\hline New Roads & No Winter Maintenance & 452995 & 410809 & 512655 \\
\hline New Roads & Three month Winter Maintenance & 487255 & 445069 & 546915 \\
\hline Old Roads & No Winter Maintenance & 856012 & 695785 & 1082607 \\
\hline Old Roads & Three month Winter Maintenance & 890272 & 730045 & 1116867 \\
\hline
\end{tabular}

over such a twenty year cycle are estimated in Annex $D$ and result in the following estimates of annualised costs:

Tab 4: The estimates of annualised costs 
The "platform width" of 6.7 metres is the average width of the surfaced area (as opposed to the carriageway width between edge lines) over the Phase 4 and Phase 5 SLRP contracts. Maintenance costs are influenced by platform width since this affects both pavement patching costs and periodic maintenance costs.

A winter maintenance requirement increases the general maintenance rate appreciably but is not a great contributor. This is because the overall maintenance costs are driven more by the pavement degradation and periodic maintenance costs than by the routine maintenance.

The rate for old roads is much higher than for new roads because the estimate foresees a serious effort in the first 5 years to bring these roads up to a reasonable pavement standard - Improvement through maintenance.

Applied to the probable LGA road holdings and assuming that the regional roads are handed to ARA these rates produce an overall annual cost of maintenance to the LGAs, based on the average of costs over 20 years, of:

Tab 5: The rates produce an overall annual cost of maintenance to the LGAs

\begin{tabular}{|l|r|r|r|}
\hline \multicolumn{4}{|c|}{ Estimated LGA Maintenance costs - without Qark Roads } \\
\hline \multicolumn{1}{|c|}{ Road Type/origin } & 1248 & 873,100 & $1,089,628,800$ \\
\hline Urban Roads - Paved & 1745 & 156,000 & $272,220,000$ \\
\hline Urban Roads - Gravel & 500 & 427,900 & $213,950,000$ \\
\hline Primary LGA Roads New Paved & 540 & 873,100 & $471,474,000$ \\
\hline Primary LGA Roads Old Paved & 5020 & 156,000 & $783,120,000$ \\
\hline Primary LGA Roads Gravel & 15150 & 44,200 & $669,630,000$ \\
\hline Secondary LGA Roads & & & $3,500,022,800$ \\
\hline Total LGA Maintenance Cost & & $\begin{array}{c}\text { Cost/km/yr } \\
\text { Total }\end{array}$ & \\
\hline
\end{tabular}

These figures are not a precise amount required by the LGAs for road maintenance but are an indication of the scale of expenditure which they will need to build up to if they are to implement comprehensive and effective road maintenance strategies designed to keep their roads in reasonable condition and to gradually upgrade their less satisfactory roads to an acceptable standard.

\section{Conclusion}

The control of routine maintenance operations does not generally require the application of test procedures other than the use of a measuring tape or stick and a straightedge.

The quality of materials for patching, pothole repair and other interventions to paved carriageways can be difficult to control adequately because the volumes are so small. In general, the only practical means of material quality control for bituminous surfacing for these purposes is to accept certification from the supplier. Because of this it is desirable to limit acceptable suppliers to those with a proven track record of satisfactory materials supply or to those who can demonstrate the acceptability of their materials through programmes of regular testing.

At its crudest, the adequacy of routine maintenance can be verified simply by driving over the road. If there are no perceivable faults then maintenance, at least in the visible aspects, is basically satisfactory. If any possible faults are observed then it becomes necessary to stop and measure defects for checking against specified requirements in respect of both the dimensions of the defect and the frequency of occurrence.

This form of visual inspection on its own is not sufficient. There are areas of the road structure which are not always visible and these too must be checked for compliance with requirements. Such areas will include drainage and culvert cleanliness 
on a regular basis and, perhaps less frequently, items such as embankment slopes, erosion around major structures and at culvert inlets and outlets, free flow in major waterways.

The key to control of routine maintenance quality is the availability and use of experienced supervisors. Supervisors need to be familiar with the roads they are controlling; they will know where problems are likely to occur, which roads are the most problematic under which conditions, which material sources give good and bad results and which elements of the labour force/contractors require closest supervision.

Properly planned road maintenance designed to keep the system in good order requires substantially more funds than are presently available. A reasonable proportion of the savings anticipated under the reforms should be allocated to improved maintenance. Improved maintenance should bring about a reduction in the level of investment in "Improvements" necessitated by lack of maintenance.

In order to ensure that some minimum level of maintenance is observed, consideration should be given to moderating the nature of the present unconditional grants and earmarking percentages of the grant for specific purposes.

Provided that adequate data regarding road conditions can be supplied, a maintenance management system will help to generate a desirable budget and through this provide a picture of the real national requirements for road maintenance expenditure. A comprehensive system can then accept an actual budget allocation for maintenance and generate the optimum distribution of that budget amongst the various parties and on the named road sections; either the LGAs alone or, if data on the national roads has been included, on both LGA and National Roads.

Such a system can either be installed at the LGA level for planning and budgeting of maintenance or a system can be established under which LGAs will report on road conditions to ADF and ADF will then analyse the road system, nationwide, and generate funding requirements and subsequent budget allocations. In any case it would seem best that ADF be in a position to analyse the whole of the LGA road system, generate desirable budgets and providing an optimum allocation of actual budgets.

\section{REFERENCES}

Bekke, H., Kickert, W. and Kooiman, J., 'Public Management and Governance' in Kickert, F. and van Vught, F. A., (eds. ), Public Policy and Administrative Sciences in the Netherlands, London: Harvester-Wheatsheaf, 1995.

Brown, R. H., 'Bureaucracy as Praxis: Toward a Political Phenomenology of Formal Organizations', 1978, Administrative Science Quarterly, vol. 23, pp. 365-382.

Cepiku, D., 'Public Governance: Overcoming the Ambiguity', in Coghill, K., (ed. ), Integrated Governance: Linking up Government, Business \& Civil Society, Monash Governance Research Unit, Monash University, Caulfield East, Melbourne, Australia, 2005.

Cepiku, D., 'La riforma della pubblica amministrazione in Albania', 2002, Azienda Pubblica, vol. 1, no. 2, pp. 155-178.

CLAD, 'A New Public Management for Latin America, Latin American Centre for Development Administration', [Online] available at http://unpan1. un. org, accessed on May 2, 2010.

Coman, P., Crai, E., Rădulescu, M. and Stănciulescu, G., 'Local Government in Romania', in Local Governments in Central and Eastern Europe, 2001.

Dragoş, D. C. and Neamţu, B., 'Reforming Local Public Administration in Romania: Trends and Obstacles', 2007, International Review of Administrative Sciences, vol. 73, no. 4. pp. 629-648.

Drechsler, W., 'The Re-Emergence of "Weberian" Public Administration after the Fall of New Public Management: The Central and Eastern European Perspective', 2005, Halduskultuur, no. 6, pp. 94-108. 
Dunleavy, P., Margetts, H., Bastow, S. and Tinkler, J., 'New Public Management is Dead - Long Live Digital-Era Governance', 2005, Journal of Public Administration Research and Theory, vol. 16, no. 3, pp. 467-494.

Dunn, W. N. and Miller, D. Y., 'A Critique of the New Public Management and the NWS: Advancing a Critical Theory of Administrative Reform', 2007, Public Organization Review, vol. 7, no. 4, pp. 345-358

Barsi, A. - Fi, I. - Lovas, T. - Melykuti, G. - Takacs, B. - Toth, C. - Toth, Z. (2005): Mobile pavement measurement system: A concept study, Proc. ASPRS Annual Conference, Baltimore, p. 8

Barsi, A. - Lovas, T. - Kertesz, I. (2006): The potential of low-end IMUs for mobile mapping systems, International Archives of Photogrammetry and Remote Sensing, Vol. XXXVI, Part 1/A+B, p. 4

Crossbow (2004): NAV420 Series User's manual I

Farrel, J. A. - Barth, M. (1999): The global positioning system \& inertial navigation, McGraw Hill, New York 